\title{
Coxsackievirus B4 vertical transmission in a murine model
}

Hela Jaïdane ${ }^{1,2^{*}} \mathbb{D}$, Aymen Halouani ${ }^{1,2}$, Habib Jmii $^{1,2}$, Firas Elmastour ${ }^{1,2}$, Moncef Mokni $^{3}$ and Mahjoub Aouni ${ }^{1}$

\begin{abstract}
Background: Life-threatening infections with type B Coxsackieviruses (CV-B) are frequently encountered among newborns and are partly attributed to vertically-transmitted virus. Our current study investigates this alternative way of contamination by CV-B, using a mouse model.

Methods: Pregnant Swiss mice were intraperitoneally inoculated with CV-B4 E2 at gestational day 10(G) or 17G. Dams and offspring were monitored for mortality and morbidity, and sampled at different time-points to document the infection and explore eventual vertical transmission.

Results: Inoculation at day $10 \mathrm{G}$ induced an important rate of abortion and a decrease in the number of delivered pups per litter, whereas inoculation at day $17 \mathrm{G}$ was marked by preterm delivery and significant behavioral changes in dams. Only one case of spastic paralysis and one case of pancreatitis were recorded among surviving pups. Seroneutralization revealed anti-CV-B4 neutralizing antibodies in infected dams and their partial transfer to offspring. Viral genome detection by RT-PCR and viral progeny titration in several tissues (dams' uteri, amniotic sac, amniotic fluid, placenta, umbilical cord, pancreas and heart) attested and documented CV-B4 vertical transmission to the majority of analyzed offspring. Virus detection in fetuses suggests transplacental transmission, but perinatal transmission during delivery could be also suggested. Vertically transmitted CV-B might even persist since prolonged viral RNA detection was noticed in the pancreas and heart from offspring born to dams inoculated at day $17 \mathrm{G}$.
\end{abstract}

Conclusion: This model of CV-B4 vertical transmission in mice, in addition to allow a better understanding of CV-B infections in fetuses and newborns, constitutes a useful tool to investigate the pathogenesis of CV-B associated chronic diseases.

Keywords: Type B Coxsackieviruses, Vertical transmission, Mouse model, Persistence

\section{Background}

Type B Coxsackieviruses (CV-B) are common encountered pathogens that, although mostly limited to asymptomatic and subclinical infections, are known for their wide tropism and for their broad spectrum of associated diseases (reviewed in [1]). Indeed, when the infection is symptomatic, it is generally localized to the gastrointestinal tract (the primary site of replication for those enteric viruses), and more rarely to the oropharynx. When virus replication persists despite the immune response,

\footnotetext{
* Correspondence: jaidanehela@yahoo.fr

'Université de Monastir, Laboratoire des Maladies Transmissibles et

Substances Biologiquement Actives LR99ES27, Faculté de Pharmacie de Monastir, Monastir, Tunisia

${ }^{2}$ Université de Tunis El Manar, Faculté des Sciences de Tunis, Tunis, Tunisia

Full list of author information is available at the end of the article
}

the virus reaches the blood circulation through mesenteric lymph nodes, then several target tissues such as heart, pancreas, spleen, liver, spinal cord, etc. Indeed, CV-B have been associated to several acute (meningitis, myocarditis, pancreatitis, encephalitis) and chronic diseases (chronic myocarditis, dilated cardiomyopathy, type 1 diabetes) that are often severe, even life-threatening, particularly in newborns and young children, thus constituting a serious public health problem [1-3].

The six $\mathrm{CV}$-B serotypes (CV-B1 to 6) belong to the Enterovirus $B$ species, from the Enterovirus genus (actually encompassing at least 271 human serotypes distributed in 7 species), of the Picornaviridae family [4, 5]. They are small, non-enveloped, icosahedral, positivesense single-stranded RNA viruses. 
Due to their resistance in the environment, $\mathrm{CV}-\mathrm{B}$ are essentially transmitted through the fecal-oral mode, and occasionally through the respiratory route [6]. The high frequency of $\mathrm{CV}-\mathrm{B}$ infections among neonates however suggests a possible vertical transmission of those viruses, at least in some cases [3, 7]. Several epidemiological, serological and virological arguments are in favor of this hypothesis. Indeed, increased levels of anti-CV-B antibodies have been found in pregnant women in association with an infection of the offspring $[8,9]$. The viral genome has also been detected in maternal and offspring tissues $[2,9,10]$. Vertical transmission of CV-B may occur either in utero (antenatally) through the transplacental way [11], or perinatally during delivery [9].

CV-B vertical transmission has been associated to an elevated risk of abortion [8, 10, 12-15] and stillbirth [16, 17]. In the case of live birth, vertically transmitted CV-B seem largely involved in many life-threatening diseases affecting fetuses, newborns and young infants $[2,3,7$, $18,19]$. On the basis of the presence of a viremia or the appearance of clinical symptoms, about $22 \%$ of fatal CV$\mathrm{B}$ infections of the neonates, result from an intra-uterine infection [7]. Moreover, maternal CV-B infections during pregnancy would predispose offspring to the development of autoimmune diseases such as type 1 diabetes [20]. Infections with CV-B during pregnancy are however generally neglected compared to those by other pathogens such as rubella virus, Zika virus, Toxoplasma, etc.....

Considering the frequency of that mode of contamination by $\mathrm{CV}-\mathrm{B}$, the width and the severity of its consequences, $\mathrm{CV}-\mathrm{B}$ vertical transmission deserves further investigation, in an attempt to develop preventive and/or therapeutic strategies. In this context, our current study aims to better explore CV-B4 vertical transmission using a mouse model.

\section{Methods \\ Virus}

The diabetogenic strain CV-B4 E2 (kindly provided by J. W. Yoon, Julia McFarlane Diabetes Research Centre, Calgary, Alberta, Canada) was propagated in HEp-2 cells (BioWhittaker, Walkersville, MD, USA) in Eagle's minimal essential medium (MEM; Gibco BRL, Invitrogen, Gaithersburg, MD, USA) supplemented with 10\% heatinactivated fetal calf serum (FCS; Gibco BRL), 1\% (2 mM) L-glutamine (BioWhittaker), $50 \mu \mathrm{g} / \mathrm{ml}$ streptomycin, $50 \mathrm{IU} / \mathrm{ml}$ penicillin (Gibco BRL), 1\% nonessential amino-acids (Gibco BRL), and 0.05\% (2.5 $\mu \mathrm{g}$ / $\mathrm{ml}$ ) fungizone (Amphotericin B, Apothecon). Supernatants were collected 3 days post-inoculation (p.i.), clarified by centrifugation at $2000 \times \mathrm{g}$ for $10 \mathrm{~min}$, divided into aliquots, and stored at $-80{ }^{\circ} \mathrm{C}$. Virus titers in stocks were determined on HEp-2 cells by limiting dilution assay for $50 \%$ tissue culture infectious doses $\left(\mathrm{TCID}_{50}\right)$ by the method of Reed and Muench [21].

\section{Mice}

All animals used in this investigation were handled in the animal facility of the Faculty of Pharmacy of Monastir, in accordance with the standards of general ethics guidelines, and maintained in specific "pathogen-free" conditions with unlimited access to food and water. Adult outbred Swiss albino mice (Pasteur Institute, Tunis) were mated (three females per male were caged together) until successful fertilization (through formation of a vaginal plug) was checked. The day the vaginal plug was observed was considered the first day of gestation (day 1G).

\section{Mice inoculation and follow-up}

Pregnant mice were inoculated intraperitoneally at two different time points, either at day 10 or 17 of gestation (day $10 \mathrm{G}$ or $17 \mathrm{G}$ ), with $2 \times 10^{5} \mathrm{TCID}_{50}$ CV-B4 E2 units contained in $200 \mu \mathrm{l}$ culture medium. Naïve mice served as negative controls. Pregnancy was monitored by daily weighing from day $10 \mathrm{G}$ until delivery. Animals were also observed for mortality, morbidity and behavioral changes. Offspring born to dams inoculated at day $10 \mathrm{G}$ were sacrificed, using isoflurane, at day $17 \mathrm{G}$ and days 0 and 5 from birth (six offspring at each time point, each three born to one different dam). By the same, those born to dams inoculated at day $17 \mathrm{G}$ were sacrificed (only if delivery occurred at least 2 days later (starting from day 19G)) at days 0 and 5 from birth, then later at days 21, 30, 50 and 70 (since, as suggested by the findings of Bopegamage et al., [22], inoculation at that pregnancy stage would have an effect easier to observe in older offspring). Amniotic fluids, placentas, internal organs from fetuses and newborn pups, then blood samples from the tail vein (for dams and for offspring at least 21 days old) were used for anti-CV-B4 antibody titration by seroneutralization. Dams' uteri, as well as umbilical cords, amniotic sacs, amniotic fluids and placentas were collected whenever possible (at day 17G), as key tissues in vertical transmission. Offspring's pancreases and hearts, spleens and small intestines were also collected. Sampled tissues were rinsed with cold PBS (to remove eventually contaminating blood) and treated for histological examination, viral RNA detection and progeny titration (spleens and small intestines were used only for histological examination).

\section{Histological analysis}

Formalin-fixed, paraffin-embedded tissues (dams' uteri, and offspring's placentas, pancreases, hearts, spleens and small intestines) were subjected to histological examination 
following hematoxylin/eosin staining, as described elsewhere [23].

\section{Antibody titration by seroneutralization}

Blood sampling being impossible in fetuses (sampled at day 17G) and newborn pups (sampled at days 0 and 5 from birth), we used the whole set of internal organs that were homogenized in an equal volume of sterile $1 \%$ penicillin/streptomycin PBS used beforehand for rinsing inside the animal after dissection. Placentas were processed separately. After $15 \mathrm{~min}$ of centrifugation at $900 \times$ $g$, the recovered supernatants were used for antibody titration, as the amniotic fluids (two samples, each one being a pool of the amniotic fluids of the three fetuses belonging to the same litter) and the sera (obtained after centrifugation of the blood sampled from dams and offspring of 21 days and older), following a recently described procedure [24]. The neutralizing titer was defined as the reciprocal of the last dilution of sample that totally inhibited the viral cytopathic effect (CPE) as observed under an inverted microscope. Results are plotted as mean neutralizing titers \pm standard deviations (SDs).

\section{Viral genome detection}

For each experimental condition (virus inoculation at day $10 \mathrm{G}$, or $17 \mathrm{G}$, and in the absence of virus inoculation), the presence of CV-B4 E2 RNA was checked at different p.i. times in the pancreas and heart of six mice (three offspring born to each of two dams) and, whenever possible (at day 17G), in placentas, amniotic fluids, and dams' uteri, according to the procedure described below.

\section{RNA extraction}

Washed and snap-frozen tissues were homogenized by crushing in Tri-Reagent (Sigma), and then centrifuged at $12,000 \times \mathrm{g}$ for $10 \mathrm{~min}$ at $4{ }^{\circ} \mathrm{C}$. Recovered supernatants were then subjected to total RNA extraction by the acid guanidium thiocyanate-phenol-chloroform procedure, as described by Chomczynski and Sacchi [25]. Sterile nuclease-free water and supernatant of CV-B4 E2infected HEp-2 cells, submitted to the same extraction procedure, served as negative and positive controls, respectively. Extracted RNA was then dissolved in $50 \mu \mathrm{l}$ of nuclease-free water (Promega), quantified using the Nanodrop 2000 (UV-Vis Spectrophotometer, Thermo Scientific) and stored at $-80{ }^{\circ} \mathrm{C}$ until use in reverse transcription (RT)-PCR assays.

\section{Two-step RT-PCR for CV-B4 E2 RNA detection}

For CV-B4 E2 RNA amplification, we used primer sense 008 : 5'-GAGTATCAATAAGCTGCTTG-3' and antisense 007: 5' -ATTGTCACCATAAGCAGCCA-3' specific of the highly conserved $5^{\prime} \mathrm{NC}$ region of enterovirus genome and generating a $414 \mathrm{bp}$ fragment [26].

cDNA synthesis was performed with about $100 \mathrm{ng}$ of RNA using $0.1 \mu \mathrm{M}$ of the anti-sense 007 primer and the M-MLV reverse transcriptase (Invitrogen), according to the manufacturer's instructions.

The PCR was carried out with $3 \mu \mathrm{l}$ of cDNA samples and $0.4 \mu \mathrm{M}$ each primer in a total volume of $50 \mu \mathrm{l}$ containing $2.5 \mathrm{U}$ of Taq Paq5000 DNA Polymerase (Agilent technologies), $0.2 \mathrm{mM}$ each $\mathrm{dNTP}$ and $2 \mathrm{mM} \mathrm{MgCl}_{2}$. The PCR mixture was subjected to a first denaturation step for $3 \mathrm{~min}$ at $94{ }^{\circ} \mathrm{C}$, followed by 30 cycles of amplification, consisting of denaturation for $20 \mathrm{~s}$ at $94{ }^{\circ} \mathrm{C}$, annealing for $20 \mathrm{~s}$ at $55{ }^{\circ} \mathrm{C}$, and extension for $30 \mathrm{~s}$ at $72{ }^{\circ} \mathrm{C}$, followed by a final extension step for $5 \mathrm{~min}$ at $72{ }^{\circ} \mathrm{C}$. All reactions were performed by using a preheated Eppendorf thermal cycler.

RNA extracted from supernatant of CV-B4 E2infected HEp-2 cells was reverse transcribed, and amplified according to the same procedure described above, and served as a positive control. A negative control (no RNA) was also included in each reaction. Samples showing negative results were subjected to beta-actin mRNA amplification, as an internal control to ensure the integrity of extracted RNA and the absence of RT-PCR inhibitors.

\section{Semi-nested (sn)-PCR}

RT-PCR products showing negative results were subjected to a subsequent sn-PCR with internal primer sense 006: 5' -TCCTCCGGCCCCTGAATGCG-3' and antisense primer 007, generating a 155 bp fragment [27]. The similar reaction mix and the same cycling program were used, except that the annealing temperature was $60{ }^{\circ} \mathrm{C}$. A positive control (DNA amplified from the RNA extract of supernatant of CV-B4 E2-infected HEp-2 cells) and a negative control (no DNA) were included in each reaction.

\section{Viral progeny titration}

For each experimental condition (virus inoculation at day $10 \mathrm{G}$, or $17 \mathrm{G}$, and in the absence of virus inoculation), infectious virus titration was performed, by the limiting dilution method, at different p.i. times (day $17 \mathrm{G}$ and days 0 and 5 from birth) in the pancreas and heart of six mice (three offspring born to each of two dams) and, whenever possible (at day 17G), in uteri, umbilical cords, amniotic sacs, amniotic fluids and placentas, according to the procedure described below. Briefly, snapfrozen tissues were weighed and crushed in $1 \%$ penicillin/streptomycin PBS, and then centrifuged at $12,000 \times \mathrm{g}$ for $10 \mathrm{~min}$ at $4{ }^{\circ} \mathrm{C}$. Supernatants were diluted 10 -fold in MEM with $2 \%$ FCS, inoculated (100 $\mu \mathrm{l})$ onto confluent HEp- 2 cells $\left(10^{4}\right.$ cells/well) in 96-well culture plates. 
Cultures were incubated at $37{ }^{\circ} \mathrm{C}$ in a humidified atmosphere with $5 \% \mathrm{CO}_{2}$ and examined daily for CV-B4 CPE up to 7 days p.i.. Cells were then stained with crystal violet for $30 \mathrm{~min}$. Finally, wells were rinsed with water and plates were examined for the highest dilution showing CPE. Viral titers were calculated according to the method of Reed and Muench [21], and expressed as mean titers $\left(\mathrm{TCID}_{50} / \mathrm{mg}\right.$ of tissue $) \pm \mathrm{SDs}$.

\section{Statistical analysis}

Data are summarized as means \pm SDs. The two-sided paired Student's $t$ test was used to compare the mean weight, at different time points, between infected and control animals. The Wilcoxon rank-sum test was used to compare the number of pups per litter between infected and control animals, as well as neutralizing antibody titers between offspring born to dams inoculated at either day $10 \mathrm{G}$ or $17 \mathrm{G}$. Statistical significance was defined by $P$-values less than 0.05 .

\section{Results}

\section{Effect of CV-B4 E2 on pregnancy outcome}

Pregnant mice were monitored by daily weighing from day $10 \mathrm{G}$ until delivery. Thus, starting from day $17 \mathrm{G}$, we observed a significant decrease $(p=0.003)$ in the weight of dams inoculated with CV-B4 E2 at day $10 \mathrm{G}$ compared to negative control pregnant dams (Fig. 1a). The weight of mice inoculated at day $17 \mathrm{G}$ remained however, until delivery, comparable to the one of negative control mice (Fig. 1a).

That decrease in the weight of dams inoculated at day $10 \mathrm{G}$ was associated to a high rate of abortion (53\%) (Fig. 1b) and to a $37 \%$ reduction in the number of offspring per litter in the remaining cases compared to negative control dams (5.77 \pm 0.93 vs. $9.25 \pm 1.04, p=0.0001$, Fig. $1 c)$.

No pregnancy loss was observed among dams inoculated at day $17 \mathrm{G}$ and the number of offspring per litter was comparable to the one in negative control dams $(8.7 \pm 0.97$ vs. $9.25 \pm 1.04$, Fig. 1c), but delivery occurred earlier since it never exceeded day 20G (days 17G, 18G, $19 \mathrm{G}$ and $20 \mathrm{G}$ in 27,36, 27 and $10 \%$ of the cases, respectively, versus day $21 \mathrm{G}$ to $22 \mathrm{G}$ in the negative control group and in dams inoculated at day 10G) (Fig. 1a).

In addition, as soon as delivery, 33\% of dams inoculated at day $17 \mathrm{G}$ were characterized by an unusual behavior, even aggressivity, which respectively manifested through abandon of their litter (pups are abandoned with their placentas and their wastes and are not breastfed), and through killing and devouring their pups.

\section{Effect of CV-B4 E2 on offspring}

No signs of morbidity were observed among offspring from CV-B4 E2-inoculated dams, except one case of spastic paralysis in a neonate pup coming from virus inoculation at day $10 \mathrm{G}$.

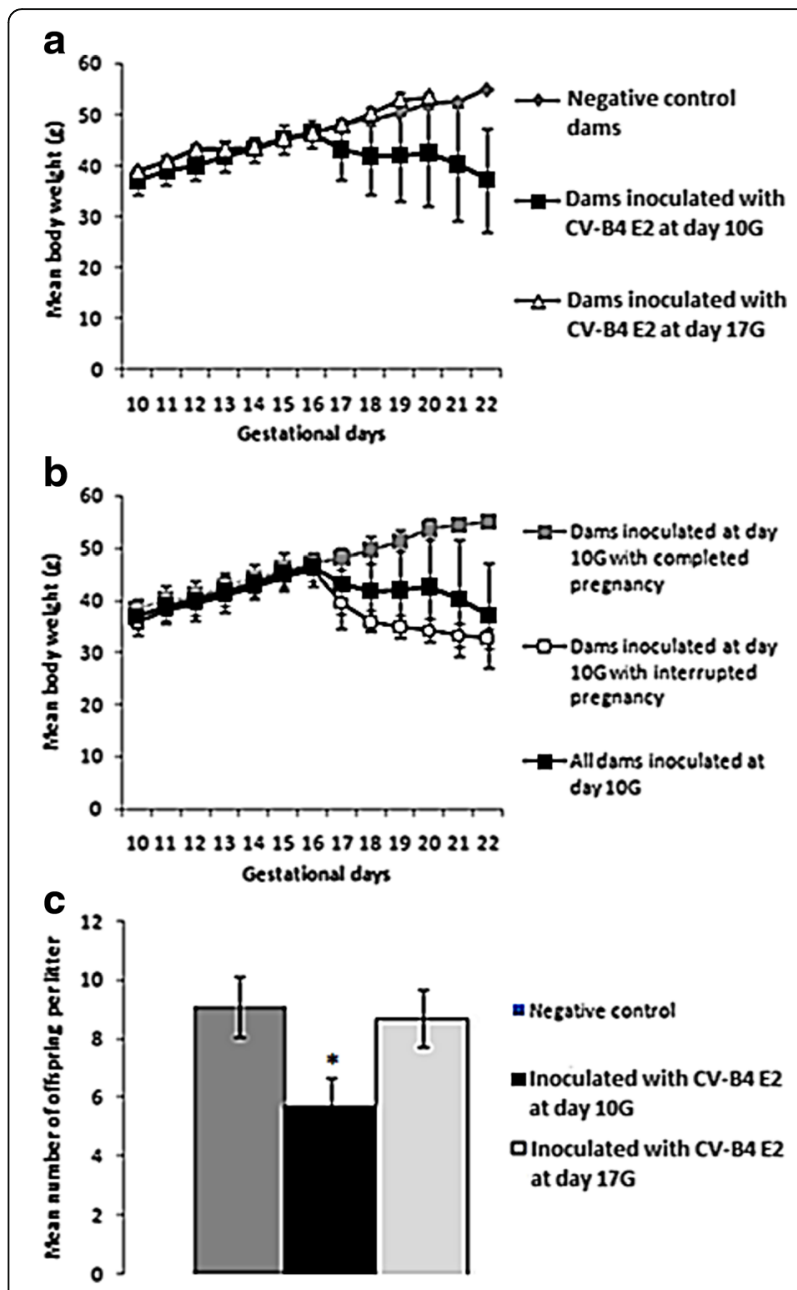

Fig. 1 Effect of CV-B4 E2 on pregnancy outcome. a Evolution of the mean body weight of dams during pregnancy depending on whether they were inoculated or not with CV-B4 E2, and at each gestational day. (Results are representative of an experiment with $n=3$ for negative control mice, $n=7$ for dams inoculated with CV-B4 E2 at day 10G, and $n=5$ for dams inoculated with CV-B4 E2 at day $17 \mathrm{G})$. $\mathbf{b}$ Evolution of the mean body weight of dams inoculated at day $10 \mathrm{G}$ depending on whether there was pregnancy loss or not (Results are representative of an experiment with $n=4$ and $n=3$, respectively). c Variation of the number of offspring per litter depending on the inoculation period. ( $n=9$ for negative controls, $n=13$ for mice inoculated at day $10 \mathrm{G}$, and $n=10$ for mice inoculated at day $17 G$

At the microscopic level, histopathological analysis revealed a unique case of pancreatitis with fatty degeneration of acinar cells on a section of a pancreas sampled at day 30 after birth in an offspring born to a dam inoculated with CV-B4 E2 at day 17G (Fig. 2).

\section{CV-B4 E2 vertical transmission}

Detection of anti-CV-B4 neutralizing antibodies in virusinoculated dams and their offspring

Before talking about a vertical transmission of CV-B4, it was essential to verify the infection of inoculated dams. 


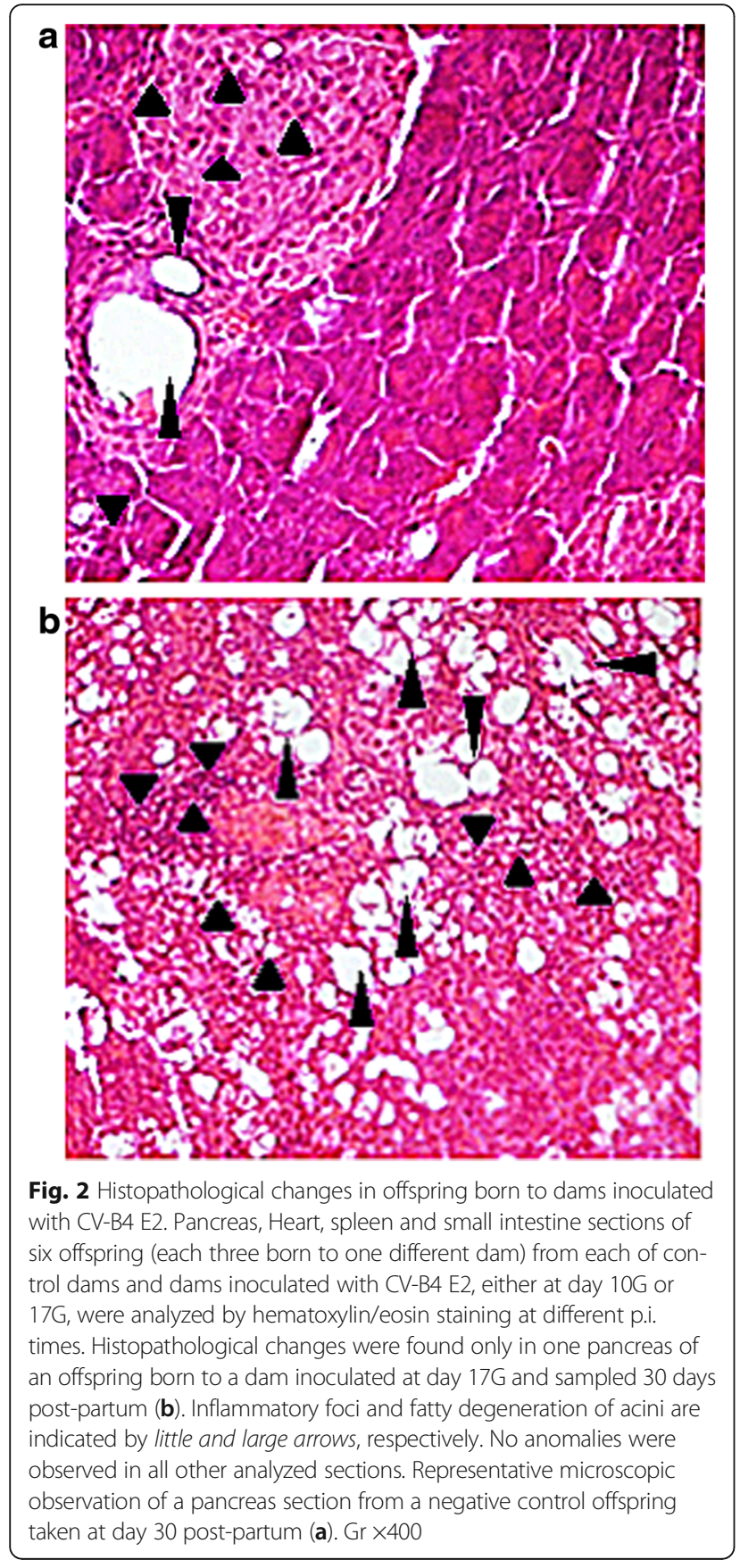

For this purpose, we searched for anti-CV-B4 neutralizing antibodies in the sera of dams inoculated either at day $10 \mathrm{G}$ ( 6 dams, 2 per time point) or day $17 \mathrm{G}$ ( 4 dams, 2 per time point) (Fig. 3a). Inoculation at day $10 \mathrm{G}$ resulted in important neutralizing titers that peaked by day 0 ( $\geq 1280,11$ to 12 days p.i.), then rapidly decreased thereafter (40 by day 5 after birth). Inoculation at day $17 \mathrm{G}$ induced low neutralizing titers (20) detectable by day 0 (only when delivery occurred at day 20G, 3 days p.i.) that increased thereafter $(\geq 1280)$ at day 5 and later (day 21, data not shown).

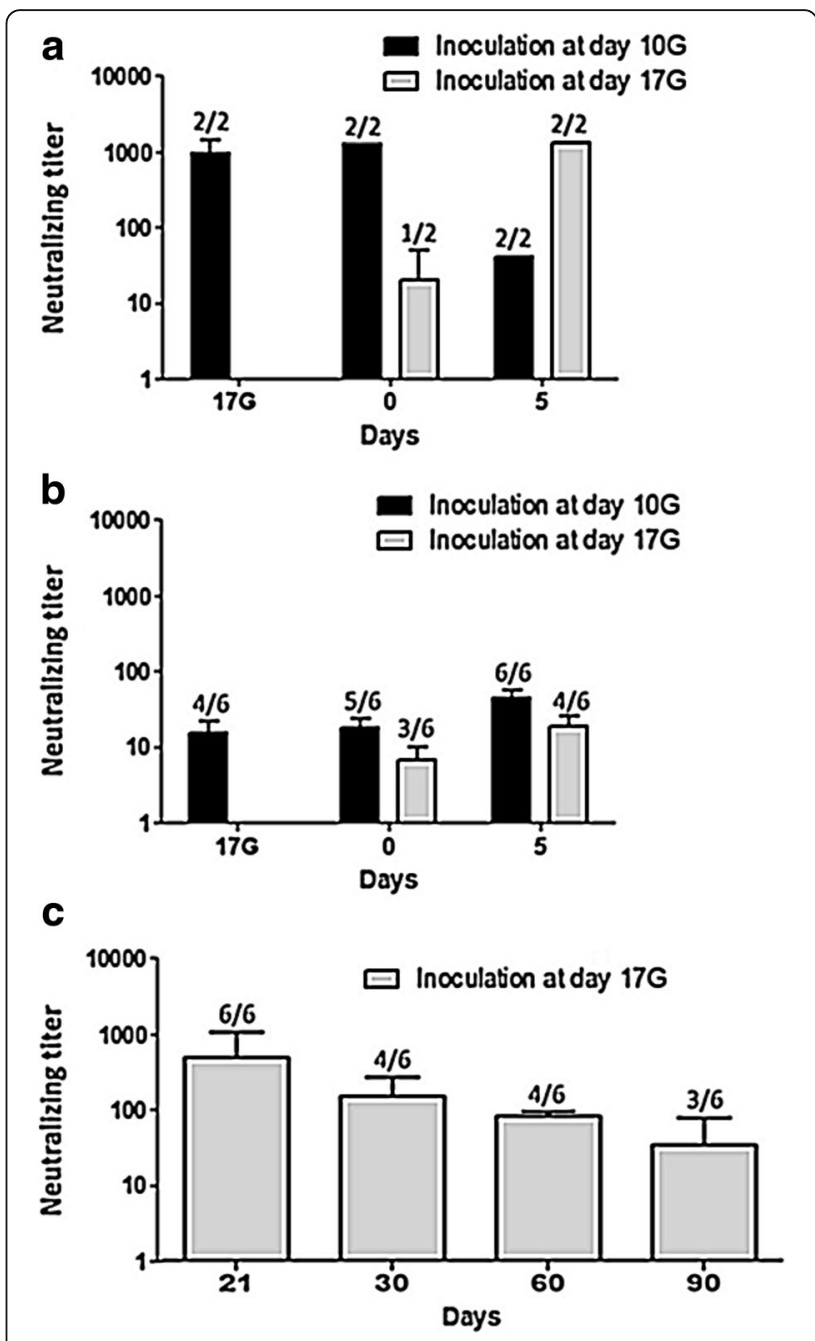

Fig. 3 Kinetics of anti-CV-B4 neutralizing antibodies after virus inoculation of pregnant dams. In order to evaluate the presence and the amount of anti-CV-B4 neutralizing antibodies, seroneutralization was performed at different time-points on (a): sera from dams inoculated with CV-B4 E2 at either day 10G or 17G, (b): supernatants of homogenized internal tissues from offspring born to dams inoculated with CV-B4 E2 at either day $10 \mathrm{G}$ or $17 \mathrm{G}$ and (c): sera from offspring (at least 21 days old) born to dams inoculated with CV-B4 E2 at day 17G. Results are plotted as mean neutralizing titers $\pm S D, n=2$ for dams and $n=6$ for offspring. The proportion of seropositive animals is indicated on each bar. Neutralizing antibodies were not detected in any sample from all negative control mice

Four out of the six placentas sampled at day $17 \mathrm{G}$ revealed positive for anti-CV-B4 neutralizing antibodies (mean titer 226.67), whereas both pooled amniotic fluids revealed negative.

Anti-CV-B4 neutralizing antibodies could also be found in offspring born to the above analyzed dams, inoculated either at day 10G or 17G (Fig. 3b). Mean neutralizing titers whilst being non-significantly higher in offspring born to dams inoculated at day 10G, where relatively low in both cases in the beginning but 
progressively increased with the increase in the proportion of seropositive animals (up to days 5 and 21 in offspring born to dams inoculated at days $10 \mathrm{G}$ and $17 \mathrm{G}$, respectively). Mean neutralizing titers then decreased over time with the decrease in the proportion of seropositive animals, but were still measurable 90 days after birth in offspring born to dams inoculated at day $17 \mathrm{G}$ (not performed in those born to dams inoculated at day 10G) (Fig. 3c).

No neutralizing activity could be evidenced in samples from negative control animals (dams and their offspring).

\section{Detection of CV-B4 genome in tissues from virus-inoculated dams and their offspring}

The presence of viral RNA was investigated in selected key tissues for vertical transmission (uterus, amniotic fluid and placenta sampled at day $17 \mathrm{G}$ ), as well as in CV-B4 privileged targets, namely pancreas and heart. Table 1 summarizes the results of RT-PCR and sn-RTPCR in those tissues sampled at different p.i. times, from two dams and three offspring of each, as described in the Methods section.

Thus, CV-B4 E2 RNA was detected in $2 / 2$ uteri, $1 / 2$ amniotic fluids and $3 / 6$ placentas, sampled at day $17 \mathrm{G}$ from animals inoculated at day 10G. Evidently, animals inoculated at day $17 \mathrm{G}$ were not sampled at that time point.

As regards the privileged target tissues of CV-B4 E2, viral RNA was found in all (18/18) pancreases sampled, from day $17 \mathrm{G}$ through day 5 after birth, in offspring born to dams inoculated at day 10G, and in 11/12 pancreases, sampled at days 0 and 5 , in offspring born to dams inoculated at day 17G. Regarding the heart, 14/18 and 10/12 tissues, sampled up to day 5 , were positive for CV-B4 E2 RNA in the case of inoculation at day $10 \mathrm{G}$ or day $17 \mathrm{G}$, respectively.

These findings reveal CV-B4 E2 vertical transmission to $18 / 18$ offspring born to dams inoculated at day $10 \mathrm{G}$, and to $11 / 12$ offspring born to dams inoculated at day $17 \mathrm{G}$.

However, as mentioned in the Methods section, pups born to dams inoculated at day $17 \mathrm{G}$ were followed for a longer period (up to day 70 after birth), to address the issue of an eventual persistence of the virus. As summarized in Table 2, CV-B4 E2 RNA was detected until 70 days after birth in $8 / 15$ pancreases sampled from day 21 through day 70 , and until 50 days after birth in $7 / 15$ hearts sampled at the same time points, thus revealing 10/15 additional offspring infected through vertical transmission of the virus from dams inoculated at day $17 \mathrm{G}$ (total 21/27).

Some samples required a subsequent sn-PCR round to reveal positive for viral RNA (22 among a total of 74 positive samples (29.73\%)).

Viral RNA was not found in samples from negative control dams and offspring.

\section{Detection of infectious CV-B4 particles in tissues from virus-inoculated dams and their offspring}

To better document the infection, a variety of tissues were analyzed for the presence of infectious virus, at

Table 1 RT-PCR results for viral RNA detection in several tissues following CV-B4 E2 inoculation

\begin{tabular}{|c|c|c|c|c|c|c|c|c|c|c|c|c|}
\hline & Sampling & & Day $17 C$ & & & Day 0 & & & Day 5 & & & \\
\hline \multirow[t]{10}{*}{ Inoculation at day $10 \mathrm{G}$} & Dams & Uterus & $+^{*}$ & & & & & & & & & Litter 1 \\
\hline & & & + & & & & & & & & & Litter 2 \\
\hline & Offspring & Amniotic fluid & $+^{*}$ & & & & & & & & & Litter 1 \\
\hline & & & - & & & & & & & & & Litter 2 \\
\hline & & Placenta & $+^{*}$ & - & - & & & & & & & Litter 1 \\
\hline & & & + & + & - & & & & & & & Litter 2 \\
\hline & & Pancreas & + & $+^{*}$ & + & + & $+^{*}$ & $+^{*}$ & + & + & $+^{*}$ & Litter 1 \\
\hline & & & + & + & + & $+^{*}$ & $+^{*}$ & + & + & + & + & Litter 2 \\
\hline & & Heart & - & + & + & + & + & $+^{*}$ & + & + & + & Litter 1 \\
\hline & & & + & - & - & $+^{*}$ & + & + & + & + & - & Litter 2 \\
\hline \multirow[t]{5}{*}{ Inoculation at day $17 \mathrm{G}$} & Offspring & Pancreas & & & & + & $+^{*}$ & + & + & + & + & Litter 1 \\
\hline & & & & & & + & + & - & + & + & + & Litter 2 \\
\hline & & Heart & & & & $+^{*}$ & + & - & + & + & $+^{*}$ & Litter 1 \\
\hline & & & & & & $+^{*}$ & $+^{*}$ & - & + & + & + & Litter 2 \\
\hline & & & pup 1 & pup 2 & pup 3 & pup 1 & pup 2 & pup 3 & pup 1 & pup 2 & pup 3 & \\
\hline
\end{tabular}

Uteri from two pregnant dams inoculated at day 10G, together with amniotic fluid (pool) and placentas of three offspring of each dam, were sampled at day $17 \mathrm{G}$. Pancreases and hearts from six offspring (each three born to one different dam) were sampled at each of days $17 \mathrm{G}$, and 0 and 5 post-partum when dams were inoculated at day $10 \mathrm{G}$, and at days 0 and 5 post-partum when dams were inoculated at day $17 \mathrm{G}$. Results are summarized as positive (+) or negative (-). ${ }^{*}$ Result obtained by sn-RT-PCR 
Table 2 RT-PCR results for prolonged viral RNA detection in pancreas and heart following CV-B4 E2 inoculation at gestational day 17

\begin{tabular}{|c|c|c|c|c|c|c|c|c|c|c|c|c|c|}
\hline & Day 21 & & & Day 30 & & & Day 50 & & & Day 70 & & & \\
\hline \multirow[t]{2}{*}{ Pancreas } & $+^{*}$ & - & - & + & + & - & - & + & $+^{*}$ & + & - & - & Litter 1 \\
\hline & - & + & + & & & & & & & & & & Litter 2 \\
\hline \multirow[t]{3}{*}{ Heart } & $+^{*}$ & - & - & + & $+^{*}$ & - & + & $+^{*}$ & - & - & - & - & Litter 1 \\
\hline & $+^{*}$ & + & - & & & & & & & & & & Litter 2 \\
\hline & pup 1 & pup 2 & pup 3 & pup 1 & pup 2 & pup 3 & pup 1 & pup 2 & pup 3 & pup 1 & pup 2 & pup 3 & \\
\hline
\end{tabular}

Pancreases and hearts from six or three offspring (each three born to one different dam) were sampled at each of days 21, 30, 50 and 70 post-partum. Results are summarized as positive (+) or negative (-). * Result obtained by sn-RT-PCR

different time points, as described in the Methods section. A viral progeny could be evidenced in samples taken from several tissues of dams inoculated at day $10 \mathrm{G}$ and their offspring, namely pancreas and heart but also umbilical cord, placenta, amniotic sac, uterus and amniotic fluid (sampled only at day 17G) (Fig. 4a). The most elevated titers were recovered from pancreas, heart, umbilical cord, placenta, then amniotic sac, uterus and amniotic fluid. The mean viral titers decreased (even nullified in the pancreas) by day 0 , then increased by day 5 after birth. As regards virus inoculation at day 17G, only offspring pancreases and hearts were analyzed and a viral progeny could also be evidenced at both day 0 and day 5 from birth (Fig. 4b). The mean viral titers increased between day 0 and day 5 and, pancreases showed higher titers than hearts.

\section{Discussion}

Vertical transmission is a way of contamination by $\mathrm{CV}-\mathrm{B}$ that, despite constituting a serious problem, as explained above, is not sufficiently recognized and not thoroughly investigated. Most of our current knowledge on this subject comes from clinical observations in humans. Few investigations on $\mathrm{CV}$-B vertical transmission were carried on mice [22, 28-33], an experimental tool however frequently used to explore various aspects of infection by those viruses, difficult to address in humans. Different viral and mice strains were used, together with different inoculation periods and routes, as well as different methods of analysis. Altogether, those studies generated numerous data, but the issue of CV-B vertical transmission is not totally elucidated and disserves further work. It is in this context that joins our current study.

As in a previous study [26], we performed our experiments with the outbred Swiss albino mouse strain for a better representation of the heterogeneity inside the human population. We equally used the viral strain $\mathrm{CV}$-B4 E2 that revealed to target numerous tissues.

The time of inoculation during pregnancy was an important point to consider since, according to previous studies, it seems to highly influence the outcome of CV$B$ infection in offspring [22, 28, 31-33]. Indeed, Dalldorf and Gifford [28], who were the first to investigate CV-B vertical transmission in mice, noticed that $\mathrm{CV}-\mathrm{B} 1$ pancreatic line intraperitoneally inoculated to mice of the Albany Standard strain in the third week of gestation, resulted in an increase in the morbidity/mortality rate among offspring (from 20 to $43 \%$ in the first and second week, respectively, to $77 \%$ in the third week), and thus to an increase in the severity of the infection at that
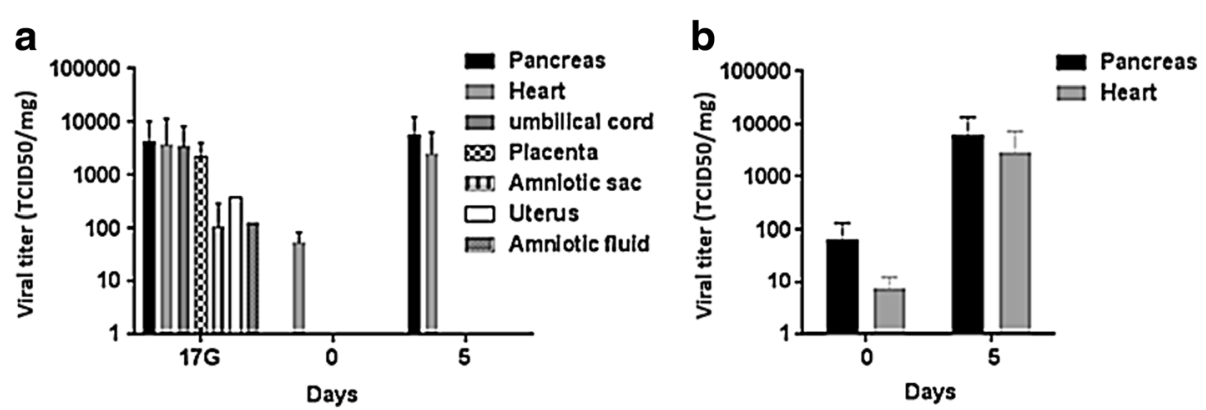

Fig. 4 Kinetics of viral progeny in several tissues following CV-B4 E2 inoculation at either gestational day 10 (a) or 17 (b). Uteri from two pregnant dams inoculated at day 10G, together with amniotic sacs, amniotic fluids (pool), umbilical cords and placentas of three offspring of each dam, were sampled at day 17G. Pancreases and hearts from six offspring (each three born to one different dam) were equally sampled at each of days $17 \mathrm{G}$, and 0 and 5 post-partum when dams were inoculated at day 10G, and at days 0 and 5 post-partum when dams were inoculated at day 17G. Samples were subjected to viral progeny titration by the Reed and Muench's method as described in the Methods section. Results are plotted as mean TCID 50 mg (except for the amniotic fluid where they are expressed as mean $\left.T C I D_{50} / \mathrm{ml}\right) \pm S D, n=6$. No trace of viral progeny could be evidenced in any tissue from all the negative control animals 
stage. Conversely, Lansdown [31] reported that intramuscular CV-B3 inoculation of Swiss mice during the first week of gestation (day $4 \mathrm{G}$ or $8 \mathrm{G}$ ) induces more pregnancy loss than an inoculation of the same virus during the second week (day 12G). Here, fetal wastage was attributed to the nutritive deficit resulting from destruction of the maternal exocrine pancreas by the virus. By the same, in the investigation carried by Modlin and Crumpacker [32] with outbred CD-1 mice, oral inoculation with CV-B1 in the first week of gestation (day 7G), despite causing a less severe infection in dams, induced significantly more abortions than inoculation in the third week (day 14G and 16G). In another investigation, also carried on CD-1 mice, maternal oral inoculation by $\mathrm{CV}$ B4 E2 at day $4 \mathrm{G}$ or day $17 \mathrm{G}$ had little effect on pregnancy outcome, whereas infection at day $10 \mathrm{G}$ affected dams and/or offspring [22]. In that same study, inoculation at day $17 \mathrm{G}$ predisposed to an aggravation of the consequences (severe pancreatic inflammations and hyperglycemia) of a post-natal challenge of pups by the same viral strain [22]. That difference in susceptibility to infection along the different gestational periods was attributed to physiological changes in hormonal rates that would be associated to a decrease in immunity [28, 32]. Variations in the level of expression of the Coxsackie/ Adenovirus receptor (CAR) protein, which revealed to be an essential molecule for the embryonic development $[34,35]$, can also explain that difference in susceptibility to $\mathrm{CV}-\mathrm{B}$ infection during the different stages of gestation. Being inspired by the results of Bopegamage et al., [22] working with the same viral strain as well as outbred mice, we chose to inoculate our mice at day $10 \mathrm{G}$ (second week) and 17G (third week of gestation).

As illustrated in the Results section, inoculation at day $10 \mathrm{G}$, but not at day $17 \mathrm{G}$, was followed by a significant weight loss in pregnant dams associated to an important rate of abortion and a reduced number of offspring per litter, which is in agreement with what has been observed previously $[22,28]$. A reduction in the mean body weight of newborn pups was also noticed following virus inoculation at day 10G (data not shown) which is reminiscent of what was previously reported in fetuses sampled at the end of pregnancy following maternal inoculation at day $8 \mathrm{G}[31,36]$. Weight loss could just reflect morbidity among infected animals or at least changes on their state of health.

Such consequences were not observed following inoculation at day $17 \mathrm{G}$, maybe because the infection occurs too late during pregnancy to affect its outcome. Inoculation at that gestational stage seems however to have more effect on dams, here manifesting through premature delivery, then unusual behavior (possibly because delivery occurs during the acute phase of the infection). An increase in susceptibility of dams to CV-B infection with advancing pregnancy has already been described by other teams [28, 32]. Cannibalism (destruction of litters by their mothers) at birth has equally been reported in one of those studies together with evident morbidity of dams for at least 1 week postpartum [28].

No delay in the fetal growth could however been evidenced as previously reported by others [36, 37], whatever was the inoculation period. By the same, morbidity among offspring manifested only in two cases in the current investigation (one case of paralysis, and one case of pancreatitis), which is negligible if we consider the total number of examined pups, and reminiscent of the results of Bopegamage et al., [22] that observed normal histology and normal blood glucose levels in offspring born to CV-B4 E2-inoculated dams.

In order to document CV-B4 E2 infection, we began with a rather simplistic approach, namely the detection of anti-CV-B4 antibodies by seroneutralization. Indeed, numerous studies documented a neutralizing response in CV-B-inoculated mice, a response that, as in humans, can be considered as an indirect proof of infection [24, 38,39 ]. It has been previously reported that $90 \%$ of pregnant CD-1 outbred Swiss mice orally inoculated with CV-B3, late in pregnancy, developed IgG antibodies to CV-B3 starting from 5 days p.i. [33]. Those antibodies seemed to protect offspring against postnatal mortality, but not against stillbirth. To the best of our knowledge, only two studies already reported maternal transfer of anti-CV-B antibodies to offspring in mice, and the effect of such antibodies seems rather contradictory and disserves further investigation [22, 40]. Indeed, passively transferred maternal antibodies enhanced the infection of offspring during challenge in the investigation of Bopegamage et al., [22], whereas they protected challenged offspring from infection in the work of Larsson et al., [40]. In our current work, anti-CV-B4 antibodies were retrieved in fetuses (day 17G) and, even after birth, roughly maintained at lower levels than in dams, which suggests a partial transplacental transfer (as strengthened by antibodies detection in the placenta) of maternal antibodies. The progressive increase in the number of seropositive pups, then their decrease after day 21, let us equally think about an additional transfer via breastfeeding, rather than a de novo synthesis by those too young animals. Indeed, the human milk was shown to contain anti-enterovirus antibodies that can neutralize the virus in vitro [41] and protect newborns from infection [42]. Although not a common diagnostic strategy, the detection of anti-CV-B5 antibodies in the amniotic fluid has been reported [43], hence the idea of including such sample in our analysis that, all the same, gave negative results. Although maternally transferred neutralizing antibodies could be responsible for the protection of our pups from morbidity and mortality, they did not prevent 
vertical transmission of the virus to them, as discussed below.

Considering the fact that the virus needs 1 to 2 days to reach fetuses $[29,30,32]$ and that offspring born to dams inoculated 1 day before delivery escape from infection [28], only tissues from offspring delivered at day $19 \mathrm{G}$ and day $20 \mathrm{G}$ were considered in the analysis for virus infection following inoculation at day $17 \mathrm{G}$.

Here we investigated CV-B4 vertical transmission by two complementary approaches, viral RNA detection and viral progeny titration (to evaluate virus replication). Both methods were concordant since revealing the same high proportion of infected offspring (18/18 and 11/12 following inoculation at day $10 \mathrm{G}$ and day $17 \mathrm{G}$, respectively, details not shown in the results of progeny titration). In a previous study with $\mathrm{CD}-1$ mice orally inoculated with CVB3, virus could be recovered from fetal tissue in only a small percentage (3 to 13\%) of pregnancies [33].

CAR is highly expressed in several fetal organs, which explains the increased susceptibility of fetuses, but equally of pregnant dams, to CV-B infections [15, 34, 35]. Several tissues can be targeted during in utero CV-B4 Infection.

Virus detection in fetuses is a direct proof of antenatal in utero virus transmission. This is supported by virus detection in key tissues in vertical transmission (uterus, amniotic sac, amniotic fluid, placenta and umbilical cord). Otherwise, perinatal transmission during delivery cannot be excluded and is often supported by the reincrease of viral titers after birth.

Infection of dams' uteri was evidenced by viral RNA detection and virus isolation in the current study, and virus isolation in a previous one [32]. An investigation outlining the involvement of CAR in the susceptibility to CV-B3 in ICR mice, showed that CAR is highly expressed in the epithelium and glands of the uterine endometrium [15], thus, making the uterus a privileged target for $\mathrm{CV}-\mathrm{B}$, as observed in the investigation of Modlin \& Crumpacker [32].

Virus detection in the amniotic fluid has already been reported in humans [2], but the current investigation gives for the first time an evidence of infection of the mouse amniotic sac and amniotic fluid.

Virus detection in the placenta and the umbilical cord, and at levels comparable to those in fetal tissues, strengthens in utero virus transmission through the transplacental way. Indeed, it was outlined that the placenta is a target for CV-B3 and CV-B4 [29, 30, 32, 33]. The failure of detecting the virus 7 days p.i. in some samples is not so intriguing since it has already been reported that virus infects the placenta 1 to 2 days after maternal infection but persists at important levels only 3 to 4 days [32].

CV-B4. E2 detection in offspring's pancreas seems rather evident for that so-called diabetogenic strain that is well known for its pancreotropism [44].
Viral RNA and progeny detection in offspring's hearts is equally not surprising since, in addition to be a main target of CV-B4, the fetal heart highly expresses CAR. That latest plays an essential role in early cardiac development and regulates cardiac remodeling in the embryo $[35,45]$. Indeed, CAR-knock-out mice die in the 11th gestational day due to cardiac anomalies $[35,46]$.

Our experimental model is the first to describe virus persistence following vertical transmission, since viral RNA could be detected until 50 and 70 days postpartum in the heart and the pancreas, respectively. In previous studies, CV-B3 [29] and CV-B4 [30] inoculated during the third week of pregnancy, were found in fetal tissues for a period that never exceeded 3 to 4 days. In the investigation by Bopegamage et al., [22], who equally used RT-PCR, no trace of infection was evident 30 days postpartum and authors did not search for the virus before that time point (what let them think that even vertical transmission did not occur). Virus persistence is considered as one of the main mechanisms leading to the development of chronic diseases associated to CV-B infections.

\section{Conclusion}

Finally, by addressing numerous issues and combining several approaches, the current report constitutes a fairly complete investigation of $\mathrm{CV}-\mathrm{B}$ vertical transmission that provides a broader and clearer picture of this still poorly known contamination route. The actually described experimental model not only allows a better understanding of CV-B infections in fetuses and newborns, but also constitutes a useful tool to investigate the genesis of CV-B associated chronic diseases, mainly those with an auto-immune component, such as type 1 diabetes, since the autoimmune process is known to be initiated as soon as fetal life.

\section{Abbreviations}

CV-B: Type B Coxsackieviruses; G: Gestational day; p.i.: Post-inoculation; sn-RTPCR: Semi-nested reverse transcription polymerase chain reaction

\section{Acknowledgements \\ The authors thank Prof Vincent GEENEN from University of Liège, Belgium, for kindly and helpful English proofreading. \\ Funding \\ This work was supported by Ministère de l'Enseignement Supérieur et de la Recherche Scientifique, (LR99ES27), Tunisi.}

\section{Availability of data and materials}

Not applicable.

\section{Authors' contributions}

$\mathrm{HJ}$ designed the study, analyzed the results and wrote the paper. $\mathrm{AH}$ performed all the experiments and analyzed the results. $\mathrm{HJ}, \mathrm{HJ}$ and FE assisted AH in experiments with the murine model and the documentation of the infection. MM supervised the experiments of anatomohistopathology and analyzed the slides. MA supervised the study and corrected the paper. All of the authors read and approved the final manuscript. 


\section{Competing interests}

The authors declare that they have no competing interests.

\section{Consent for publication}

Not applicable.

\section{Ethics approval and consent to participate}

All applicable international, national and/or institutional guidelines for the care and use of animals were followed. All procedures performed in studies involving animals were approved by the Faculty of Pharmacy of Monastir, University of Monastir, Tunisia.

\section{Author details}

${ }^{1}$ Université de Monastir, Laboratoire des Maladies Transmissibles et Substances Biologiquement Actives LR99ES27, Faculté de Pharmacie de Monastir, Monastir, Tunisia. ${ }^{2}$ Université de Tunis El Manar, Faculté des Sciences de Tunis, Tunis, Tunisia. ${ }^{3}$ Université de Sousse, CHU Farhat Hached, Service d'Anatomopathologie, Sousse, Tunisia.

\section{Received: 26 September 2016 Accepted: 18 January 2017}

Published online: 31 January 2017

\section{References}

1. Tracy S, Gauntt C. Group B coxsackievirus virulence. In: Tracy S, Chapman NM, Mahy BWJ, editors. The Coxsackie B Viruses. Curr Top Microbiol Immunol. 2008;323:49-63

2. Kaplan MH, Klein SW, McPhee J, Harper RG. Group B coxsackievirus infections in infants younger than three months of age: a serious childhood illness. Rev Infec Dis. 1983;5:1019-32.

3. Modlin JF, Rotbart HA. Group B coxsackie disease in children. In: Tracy S, Chapman NM, Mahy BWJ, editors. The Coxsackie B Viruses. Curr Top Microbiol Immunol. 1997;223:53-80

4. Knowles NJ, Hovi T, Hyypiä T, King AMQ, Lindberg AM, Pallansch MA, Palmenberg AC, Simmonds P, Skern T, Stanway G, Yamashita T, Zell R. Picornaviridae. In: King AMQ, Adams MJ, Carstens EB, Lefkowitz EJ, editors. Virus taxonomy: classification and nomenclature of viruses: ninth report of the International Committee on Taxonomy of Viruses. San Diego: Elsevier; 2012. p. 855-80.

5. Adams MJ, King AMQ, Carstens EB. Ratification vote on taxonomic proposals to the International Committee on Taxonomy of Viruses (2013). Arch Virol. 2013;158:2023-30

6. Mahy BWJ. Coxsackie B viruses: an introduction. In: Tracy S, Oberste S, Drescher KM, editors. Group B Coxsackieviruses. Curr Top Microbiol Immunol. 2008;323:vii-xiii

7. Abzug MJ. Presentation, diagnosis, and management of enterovirus infections in neonates. Paediatr Drugs. 2004;6:1-10.

8. Frisk $\mathrm{G}$, Diderholm $\mathrm{H}$. Increased frequency of coxsackie $B$ virus IgM in women with spontaneous abortion. J Infect. 1992;24:141-5.

9. Bendig JW, Franklin OM, Hebden AK, Backhouse PJ, Clewley JP, Goldman AP, Piggott N. Coxsackievirus B3 sequences in the blood of a neonate with congenital myocarditis, plus serological evidence of maternal infection. J Med Virol. 2003;70:606-9.

10. Basso NG, Fonseca ME, Garcia AG, Zuardi JA, Silva MA, Outani H. Enterovirus isolation from foetal and placental tissues. Acta Virol. 1990;34:49-57.

11. Konstantinidou A, Anninos H, Spanakis N, Kotsiakis X, Syridou G, Tsakris A, Patsouris E. Transplacental infection of Coxsackievirus B3 pathological findings in the fetus. J Med Virol. 2007;79:754-7.

12. Axelsson C, Bondestam K, Frisk G, Bergstrom S, Diderholm H. Coxsackie B virus infections in women with miscarriage. J Med Virol. 1993;39:282-5.

13. El-Esnawy NA, Ali MA, Bayoumi FS, Abo-El-Khir A, Abdel-Wahab KS. Waterborne viruses associated with repeated abortion. J Egypt Public Health Assoc. 2001:76(5-6):487-503.

14. Jiang WL, Liu Z, Yang ZQ, Xu SX, Luo XL. [Investigation of viral pathogens contributing to habitual abortion]. Nan Fang Yi Ke Da Xue Xue Bao. 2006; 26(7):1020-2.

15. Hwang JH, Kim JW, Hwang JY, Lee KM, Shim HM, Bae YK, Paik SS, Park H. Coxsackievirus B infection is highly related with missed abortion in Korea. Yonsei Med J. 2014;55(6):1562-7.

16. Burch GE, Sun SC, Chu KC, Sohal RS, Colcolough HL. Interstitial and coxsackie B myocarditis in infants and children. J Am Med Assn. 1968;203:1-8.
17. McClure EM, Goldenberg RL. Infection and stillbirth. Semin Fetal Neonatal Med. 2009;14(4):182-9.

18. Euscher E, Davis J, Holzman I, Nuovo GJ. Coxsackie virus infection of the placenta associated with neurodevelopmental delays in the newborn. Obstet Gynecol. 2001;98(6):1019-26.

19. Satosar A, Ramirez NC, Bartholomew D, Davis J, Nuovo GJ. Histological correlates of viral and bacterial infection of the placenta associated with severe morbidity and mortality in the newborn. Hum Pathol. 2004;35(5):536-45.

20. Dahlquist G, Ivarsson SA, Lindberg B, Forsgren M. Maternal enteroviral infection during pregnancy as a risk factor for childhood IDDM. A population based case-control study. Diabetes. 1996;44:408-13.

21. Reed $\amalg$, Muench $H$. A simple method of estimating fifty percent endpoints. Am J Hyg. 1938;27:493-7.

22. Bopegamage S, Precechtelova J, Marosova L, Stipalova D, Sojka M, Borsanyiova M, Gomolcak P, Berakova K, Galama JM. Outcome of challenge with coxsackievirus B4 in young mice after maternal infection with the same virus during gestation. FEMS Immunol Med Microbiol. 2012;64:184-90.

23. Elmastour F, Jaidane H, Benkahla M, Aguech-Oueslati L, Sane F, Halouani A, Engelmann I, Bertin A, Mokni M, Gharbi J, Aouni M, Alidjinou EK, Hober D. Anti-coxsackievirus B4 (CV-B4) enhancing activity of serum associated with increased viral load and pathology in mice reinfected with CV-B4. Virulence. 2016;28:1-16 [Epub ahead of print].

24. Elmastour F, Jaidane $H$, Aguech-Oueslati L, Benkahla MA, Aouni M, Gharbi J, Sane F, Hober D. Immunoglobulin G-dependent enhancement of the infection with Coxsackievirus B4 in a murine system. Virulence. 2016;7:527-35.

25. Chomczynski P, Sacchi N. Single-step method of RNA isolation by acid guanidinium thiocyanate-phenol-chloroform extraction. Anal Biochem. 1987; 162:156-9.

26. Jaïdane H, Gharbi J, Lobert PE, Lucas B, Hiar R, M'hadheb MB, Brilot F, Geenen V, Aouni M, Hober D. Prolonged viral RNA detection in blood and lymphoid tissues from Coxsackievirus B4 E2 orally inoculated Swiss mice. Microbiol Immunol. 2006;50:971-4.

27. Zoll GJ, Melchers WJ, Kopecka H, Jambroes G, Van Der Poel HJ, Lama JM. General primer-mediated polymerase chain reaction for detection of enteroviruses: application for diagnostic routine and persistent infections. J Clin Microbiol. 1992;30:160-5.

28. Dalldorf G, Gifford R. Susceptibility of gravid mice to Coxsackie virus infection. J Exp Med. 1954;99(1):21-7.

29. Soike K. Coxsackie B-3 virus infection in the pregnant mouse. J Infect Dis. 1967;117(3):203-8.

30. Selzer G. Transplacental infection of the mouse fetus by Coxsackie viruses. Isr J Med Sci. 1969;5(1):125-7.

31. Lansdown AB. Influence of time of infection during pregnancy with coxsackievirus B3 on maternal pathology and foetal growth in mice. Br J Exp Pathol. 1975;56:119-23.

32. Modlin JF, Crumpacker CS. Coxsackievirus B infection in pregnant mice and transplacental infection of the fetus. Infect Immun. 1982;37(1):222-6.

33. Modlin JF, Bowman M. Perinatal Transmission of Coxsackievirus B3 in Mice. J Infect Dis. 1987;156(1):21-5.

34. Honda T, Saitoh H, Masuko M, Katagiri-Abe T, Tominaga K, Kozakai I, Kobayashi K, Kumanishi T, Watanabe YG, Odani S, Kuwano R. The coxsackievirus-adenovirus receptor protein as a cell adhesion molecule in the developing mouse brain. Brain Res Mol Brain Res. 2000;77(1):19-28.

35. Dorner AA, Wegmann F, Butz S, Wolburg-Buchholz K, Wolburg H, Mack A, Nasdala I, August B, Westermann J, Rathjen FG, Vestweber D. Coxsackievirus-adenovirus receptor (CAR) is essential for early embryonic cardiac development. J Cell Sci. 2005;118(Pt 15):3509-21.

36. Coid CR, Ramsden DB. Retardation of foetal growth and plasma protein development in foetuses from mice injected with Coxsackie B3 virus. Nature. 1973;241(5390):460-1.

37. Lansdown $A B$, Coid CR. Pathological changes in pregnant mice infected with Coxsackie B3 virus as a possible cause of retarded foetal development. Br J Exp Path. 1974;55:101.

38. Bopegamage $S$, Borsanyiová M, Vargová A, Petrovicová A, Benkovicová M, Gomolcák P. Coxsackievirus infection of mice. I. Viral kinetics and histopathological changes in mice experimentally infected with coxsackieviruses B3 and B4 by oral route. Acta Virol. 2003;47(4):245-51.

39. Jrad-Battikh N, Souii A, Oueslati L, Aouni M, Hober D, Gharbi J, Ben M'hadheb-Gharbi M. Neutralizing activity induced by the attenuated coxsackievirus B3 Sabin3-like strain against CV-B3 infection. Curr Microbiol. 2014;68(4):503-9. 
40. Larsson PG, Lakshmikanth $T$, Svedin E, King C, Flodström-Tullberg M. Previous maternal infection protects offspring from enterovirus infection and prevents experimental diabetes development in mice. Diabetologia. 2013:56(4):867-74.

41. Sané F, Alidjinou EK, Kacet N, Moukassa D, Charlet C, Ebatetou-Ataboho E, Ngoulou W, Badia-Boungou F, Romond MB, Hober D. Human milk can neutralize Coxsackievirus B4 in vitro. J Med Virol. 2013;85(5):880-7.

42. Sadeharju K, Knip M, Virtanen SM, Savilahti E, Tauriainen S, Koskela P, Akerblom HK, Hyöty H, Finnish TRIGR Study Group. Maternal antibodies in breast milk protect the child from enterovirus infections. Pediatrics. 2007; 119(5):941-6.

43. Evaldson G, Blomberg I, Grillner L, Nord CE, Weintraub A. The role of immunoglobulins in amniotic fluid growth inhibition of Bacteroides fragilis, herpes simplex, coxsackie B5 and cytomegalovirus. Med Microbiol Immunol. 1983;172(3):155-60.

44. Yoon JW, Austin M, Onodera T, Notkins AL. Isolation of a virus from the pancreas of a child with diabetic ketoacidosis (virus-induced diabetes mellitus). New Engl J Med. 1979;300:1173-9.

45. Fischer R, Poller W, Schultheiss HP, Gotthardt M. CAR-diology-a virus receptor in the healthy and diseased heart. J Mol Med Berl. 2009;87:879-84.

46. Chen JW, Zhou B, Yu QC, Shin SJ, Jiao K, Schneider MD, Baldwin HS, Bergelson JM. Cardiomyocyte-specific deletion of the coxsackievirus and adenovirus receptor results in hyperplasia of the embryonic left ventricle and abnormalities of sinuatrial valves. Circ Res. 2006;98:923-30.

\section{Submit your next manuscript to BioMed Central} and we will help you at every step:

- We accept pre-submission inquiries

- Our selector tool helps you to find the most relevant journal

- We provide round the clock customer support

- Convenient online submission

- Thorough peer review

- Inclusion in PubMed and all major indexing services

- Maximum visibility for your research

Submit your manuscript at www.biomedcentral.com/submit 